\title{
SIMULATION AND ANALYSIS OF DIFFERENT PIEZOELECTRIC MATERIALS IN MEMS CANTILEVER FOR ENERGY HARVESTING
}

\author{
Abdul Aziz Khan $\mathrm{J}^{1 *}$, Shanmugaraja $\mathrm{P}^{2}$, Kannan $\mathrm{S}^{3}$ \\ ${ }^{1}$ Research Scholar, Department of Electronics and Communication Engineering, Annamalai University, Annamalainagar 608002, \\ India \\ ${ }^{2}$ Professor, Department of Electronics and Instrumentation Engineering, Annamalai University, Annamalainagar 608002, India \\ ${ }^{3}$ Research Scholar, Department of Electronics and Instrumentation Engineering, Annamalai University, Annamalainagar 608002, \\ India \\ jahanaziz858@gmail.com ${ }^{1}$,psraja70@gmail.com ${ }^{2}$, kannan.blitz@gmail.com ${ }^{3}$
}

\begin{abstract}
MEMS Energy Harvesting(EH) devices are excepted to grow in the upcoming years, due to the
\end{abstract} increasing aspects of MEMS EH devices in vast applications. In Recent advancements in energy harvesting (EH) technologies wireless sensor devices play a vital role to extend their lifetime readily available in natural resources. In this paper the design of MEMS Cantilever at low frequency $(100 \mathrm{~Hz})$ with different piezoelectric materials Gallium Arsenide (GaAs), Lead Zirconate Titanate (PZT-8), Tellurium Dioxide (TeO2), Zinc oxide $(\mathrm{ZnO})$ is simulated and performance with different materials are compared. The results are analyzed with various parameters such as electric potential voltage, von mises stress, displacement. The paper discusses the suitability of the piezoelectric material for MEMS fully cochlear implantable sensor application.

\section{Keywords}

MEMS Energy Harvesting, Piezoelectric Materials, Cochlear Implantable sensor.

\section{INTRODUCTION}

Micro-electro-mechanical systems(MEMS) is a rapidly emerging technology that plays a major role due to its magnificent features which interface the physical world and the electronic world in our day-to-day life. It allows mechanical devices to be miniaturized in the range of microlevel which is equivalent to our human hair. Micromachining is the most important technique used for fabrication in microelectromechanical devices for integrated circuits. MEMS instantly uses common mechanical parts such as channels, diaphragms, cantilevers, membranes, grooves, springs, gears, suspensions, and other complex structures. The MEMS cantilever beam was constrained at one end and kept free at another end. When a force is applied, the cantilever deflects which results in displacement and stress within the beam. The common material used for fabricating process is silicon as a substrate. The main advantage is reduced volume and weight, increased performance, reliability and decreased cost, easy to integrate, low power consumption, improved thermal expansion, highly resistant to vibration and radiation [1]. Many MEMS devices are fabricated and shipped in commercial volume such as pressure sensor, accelerometer, micro-valve, projection display chips, biosensors, inkjet nozzle arrays, electrical arrays, optical fiber switching, fluid control etc [2]. Energy harvesting can be known as power harvesting or energy scavenging which is used for lowpowered electronic devices, and to replace batteries due to high cost, reliability, frequent power, and to increase its life span. Energy harvesting is the process of converting small amounts of readily available energy into usable electrical energy; this can be stored or conditioned for direct usage [3]. The efficiency of the energy harvester is based on the type of material to be coated on the substrate. Piezoelectric Energy Harvesting (PEH) is broadly used as the area of research due to its simple structure and self-power sources for sensors. The geometry of piezoelectric cantilever determines the vibrational energy harvesting ability. In recent developments, most of the $\mathrm{PEH}$ is primarily used with MEMS technology and it has applications in various areas like wireless sensors, monitoring systems and medical implantable sensors etc [4].

In this paper an unimorph MEMS piezoelectric rectangular cantilever beam is designed and simulated using COMSOL Multiphysics to convert mechanical energy into electrical energy. The Eigen frequency analysis of the cantilever beam is obtained at low frequency of $100 \mathrm{~Hz}$ [5]. The results obtained in COMSOL Multiphysics the parameters such as von mises stress, displacement, and electric potential voltage with different piezoelectric material are compared and a detailed study has been done to find the suitability of the material to be implemented in the cochlear implantable device [7]. 


\section{DESIGN PARAMETERS}

2.1 Structure of MEMS Piezoelectric Energy harvester The unimorph piezoelectric energy harvester is designed with Poly-Silicon substrate as bottom layer and different piezoelectric materials like Gallium Arsenide(GaAs), Lead Zirconate Titanate(PZT-8), Tellurium Dioxide(TeO2), Zinc oxide $(\mathrm{ZnO})$ as top layer [7]. The two materials are bonded perfectly in $\mathrm{X}, \mathrm{Y}$ and $\mathrm{Z}$ directions. One end of the cantilever beam with $X$-axis along its length is fixed at $\mathrm{x}=0$; another end along the thickness is kept free to deflect on the $\mathrm{Z}$-axis. The length $(\mathrm{X})$ varies, the width $(\mathrm{Y})$ and thickness $(\mathrm{Z})$ of the beam are kept constant $(900 \mu \mathrm{m}, 5 \mu \mathrm{m})$ for different piezoelectric cantilever

[8].

$$
\text { beams }
$$

\section{Pressure}
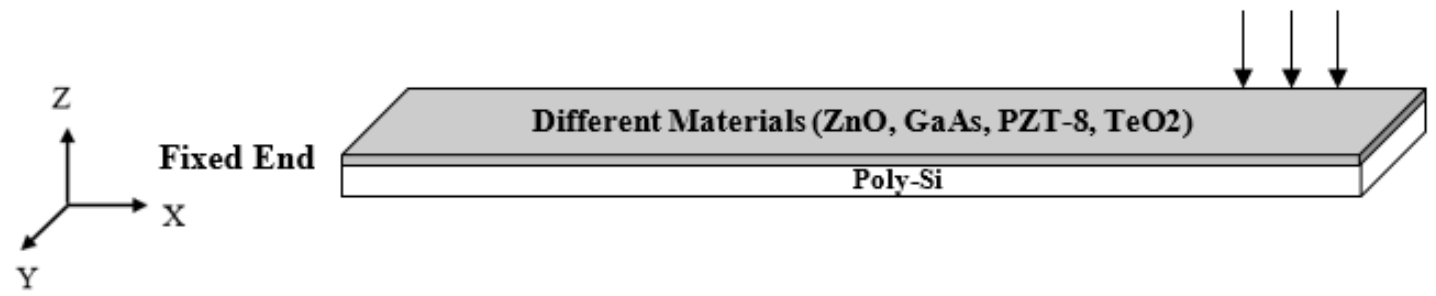

Figure 1. (a) Schematic view of Piezoelectric Cantilever beam.

\subsection{Stress charge form for piezoelectric material}

Piezoelectric material produces electrical charge when it is mechanically deformed. The piezoelectric energy harvester is governed by the following equations written in the stresscharge format [9].

$$
\begin{aligned}
& \mathrm{T}=\mathrm{C}_{\mathrm{E}} \mathrm{S}+\mathrm{eE} \\
& \mathrm{D}=\mathrm{e}^{\mathrm{T}} \mathrm{S}+\varepsilon_{\mathrm{s}} \mathrm{E}
\end{aligned}
$$

Where $\mathbf{S}$ is the strain vector; $\mathbf{T}$ is the stress vector; $\mathbf{D}$ is the electric flux density vector; $\mathbf{E}$ is the electric field vector; $\mathbf{C}_{\mathbf{E}}$ is the elasticity matrix; $\mathbf{e}$ is the piezoelectric stress matrix; $\boldsymbol{\varepsilon}_{\mathbf{s}}$ is the dielectric matrix.

\subsection{Material Properties}

PEH is a mechanism used to harvest vibration from ambience to direct usable electrical energy. The piezoelectric material converts mechanical strain to electrical power that can be used for small and large power densities.

Table 1: Physical properties of PZT materials

\begin{tabular}{|l|c|c|c|}
\hline PZT Materials & $\begin{array}{c}\text { Young's } \\
\text { Modulus } \\
{[\mathbf{x 1 0}]}\end{array}$ & $\begin{array}{c}\text { Density } \\
{\left[\mathbf{k g} / \mathbf{m}^{\wedge} \mathbf{3}\right]}\end{array}$ & $\begin{array}{c}\text { Poison's } \\
\text { ratio }\end{array}$ \\
\hline Gallium Arsenide & 82.68 & 5307 & 0.31 \\
\hline $\begin{array}{l}\text { Lead Zirconate } \\
\text { Titanate (PZT-8) }\end{array}$ & 63 & 7600 & 0.31 \\
\hline Tellurium Dioxide & 76.092 & 5990 & 0.651 \\
\hline Zinc oxide & 195 & 5680 & 0.358 \\
\hline
\end{tabular}

The piezoelectric cantilever beam under study is tested with the four different PZT materials: Zinc oxide, Lead Zirconate Titanate (PZT-8), Tellurium

Dioxide deposited on the top layer. The physical and material properties are reported in Table 1 and Table 2.

Table 2.Piezoelectric Material Properties1. Elasticity Matrix (cE) x10 ${ }^{10} \mathrm{~Pa}$ 


\begin{tabular}{|c|c|c|c|c|c|c|c|c|c|c|c|}
\hline Г20.9714 & 12.114 & 10.5359 & 0 & 0 & & 「11.9263 & 5.99859 & 11.9263 & 0 & 0 & \\
\hline 20.9714 & 10.5359 & 0 & 0 & 0 & & 5.99859 & 5.99859 & 0 & 0 & 0 & \\
\hline 21.1194 & 0 & 0 & 0 & 0 & & 11.9263 & 0 & 0 & 0 & 0 & \\
\hline 0 & 0 & 0 & 4.23729 & 0 & & 0 & 0 & 0 & 5.37634 & 0 & \\
\hline 0 & 0 & 0 & 0 & 4.2372 & & 0 & 0 & 0 & 0 & 5.37634 & \\
\hline 0 & 0 & 0 & 0 & 0 & 4.4 & 0 & 0 & 0 & 0 & 0 & 5.3 \\
\hline \multicolumn{12}{|c|}{ GaAs } \\
\hline [14.6876 & 8.1087 & 14.6876 & 0 & 0 & 0 & {$[5.70042$} & 5.24587 & 5.70042 & 0 & 0 & \\
\hline 8.10537 & 8.10537 & 0 & 0 & 0 & 0 & 2.2424 & 2.2424 & 0 & 0 & 0 & \\
\hline 13.1712 & 0 & 0 & 0 & 0 & 0 & 10.6275 & 0 & 0 & 0 & 0 & \\
\hline 0 & 0 & 0 & 3.1348 & 0 & 0 & 0 & 0 & 0 & 2.65252 & 0 & \\
\hline 0 & 0 & 0 & 0 & 3.1348 & 0 & 0 & 0 & 0 & 0 & 2.65252 & \\
\hline 0 & 0 & 0 & 0 & 0 & $3.28 \mathrm{c}$ & 0 & 0 & 0 & 0 & 0 & 6.5 \\
\hline \multicolumn{8}{|c|}{ P7T_8 } & \multicolumn{3}{|l|}{$\mathrm{TeO}_{2}$} & \\
\hline
\end{tabular}

\section{Coupling Matrix (eES) $\mathrm{C} / \mathrm{m}^{2}$}

$\left[\begin{array}{cccccc}0 & 0 & -0.567005 & 0 & 0 & -0.5670 \\ 0 & 0 & 1.32044 & 0 & -0.480508 & 0 \\ -0.480508 & 0 & 0 & 0 & 0 & 0\end{array} \quad\left[\begin{array}{cccccc}0 & 0 & 0 & 0 & 0 & 0 \\ 0 & 0 & 0.139785 & 0 & 0 & 0 \\ 0.139785 & 0 & 0 & 0 & 0 & 0.139785\end{array}\right]\right.$

\section{$\mathrm{ZnO}$}

GaAs

$\left[\begin{array}{cccccc}0 & 0 & -3.87538 & 0 & 0 & -3.87538 \\ 0 & 0 & 13.9108 & 0 & 10.34480 & 0 \\ 10.3448 & 0 & 0 & 0 & 0 & 0\end{array}\right] \quad\left[\begin{array}{cccccc}0 & 0 & 0 & 0 & 0 & 0 \\ 0 & 0 & 0 & 0.21565 & 0 & 0 \\ 0 & -0.21565 & 0 & 0 & 0 & 0\end{array}\right]$

PZT-8

$\mathrm{TeO}_{2}$

\section{Relative permittivity $\left(\varepsilon_{\mathrm{rs}}\right)$}

$$
\begin{gathered}
{\left[\begin{array}{ccc}
8.5446 & 0 & 0 \\
0 & 8.5446 & 0 \\
0 & 0 & 10.204
\end{array}\right]} \\
{\left[\begin{array}{ccc}
904.4 & 0 & 0 \\
0 & 904.4 & 0 \\
0 & 0 & 561.6
\end{array}\right]}
\end{gathered}
$$

\section{PZT-8}

\section{MODELING}

\subsection{Displacement Modeling}

Pressure is applied in the Z-axis direction, the displacement on $\mathrm{Z}$-axis component of the beam induces sensitivity thereby stress or strain is produced due to one Pascal on boundary load [10]. The inverse of the radius of curvature(r) can be expressed in below equation 3 .

$$
\left[\begin{array}{ccc}
12.459 & 0 & 0 \\
0 & 12.459 & 0 \\
0 & 0 & 12.459
\end{array}\right]
$$

GaAs

$$
\left[\begin{array}{ccc}
22.702 & 0 & 0 \\
0 & 22.702 & 0 \\
0 & 0 & 24.7
\end{array}\right]
$$

$\mathrm{TeO}_{2}$

$$
\frac{1}{\mathrm{r}}=\frac{\mathrm{d}^{2} \mathrm{~h}(\mathrm{x})}{\mathrm{dx}^{2}}=\frac{\mathrm{M}(\mathrm{x})}{\mathrm{WD}_{1}}=-\frac{\mathrm{F}}{2 \mathrm{WD}_{1}}[\mathrm{~L}-\mathrm{x}]^{2}
$$

The $x$ varies from $0<x<\mathrm{L}$, where $h(x)=$ Axial Displacement, $M(x)=$ Bending moment of the cantilever, $D_{1}$ is the Bending Modulus per unit width and can be expressed as equation 4 .

$D_{1}=\frac{E_{s}^{2} t_{s}^{4}+E_{p}^{2} t_{p}^{4}+2 E_{s} E_{p} t_{s} t_{p}\left(2 t_{s}^{2}+2 t_{p}^{2}+3 t_{s} t_{p}\right)}{12\left(E_{s} t_{s}+E_{p} t_{p}\right)}$ 
Where, $E_{s}$ and $E_{p}$ are the Young's Modulus of polysilicon substrate and Piezoelectric layer. The parameters $t_{s}, t_{p}$ are the thickness of the polysilicon substrate and piezoelectric layer.

$$
h_{\text {tip }}=-\frac{F}{W D_{1}}\left[\frac{L^{3}}{8}\right]
$$

In equation 5, $\mathrm{W} \& \mathrm{~L}$ are width and length of the Poly-silicon and one Pascal $(\mathrm{Pa})$ force $(\mathrm{F})$ is applied in terms of pressure $(\mathrm{P})$. Stiffness constant $(\mathrm{K})$ of the beam is defined as the force required for unit tip displacement can be derived from equation (6).

$$
K=\frac{F_{a}}{h_{\text {tip }}}=\frac{8 W D_{1}}{L^{3}}
$$

\subsection{Frequency Response}

The resonant frequency of cantilever beam simulated at $100 \mathrm{~Hz}$ is calculated manually by equation 8,9 and compared using Comsol Multiphysics.

(a)
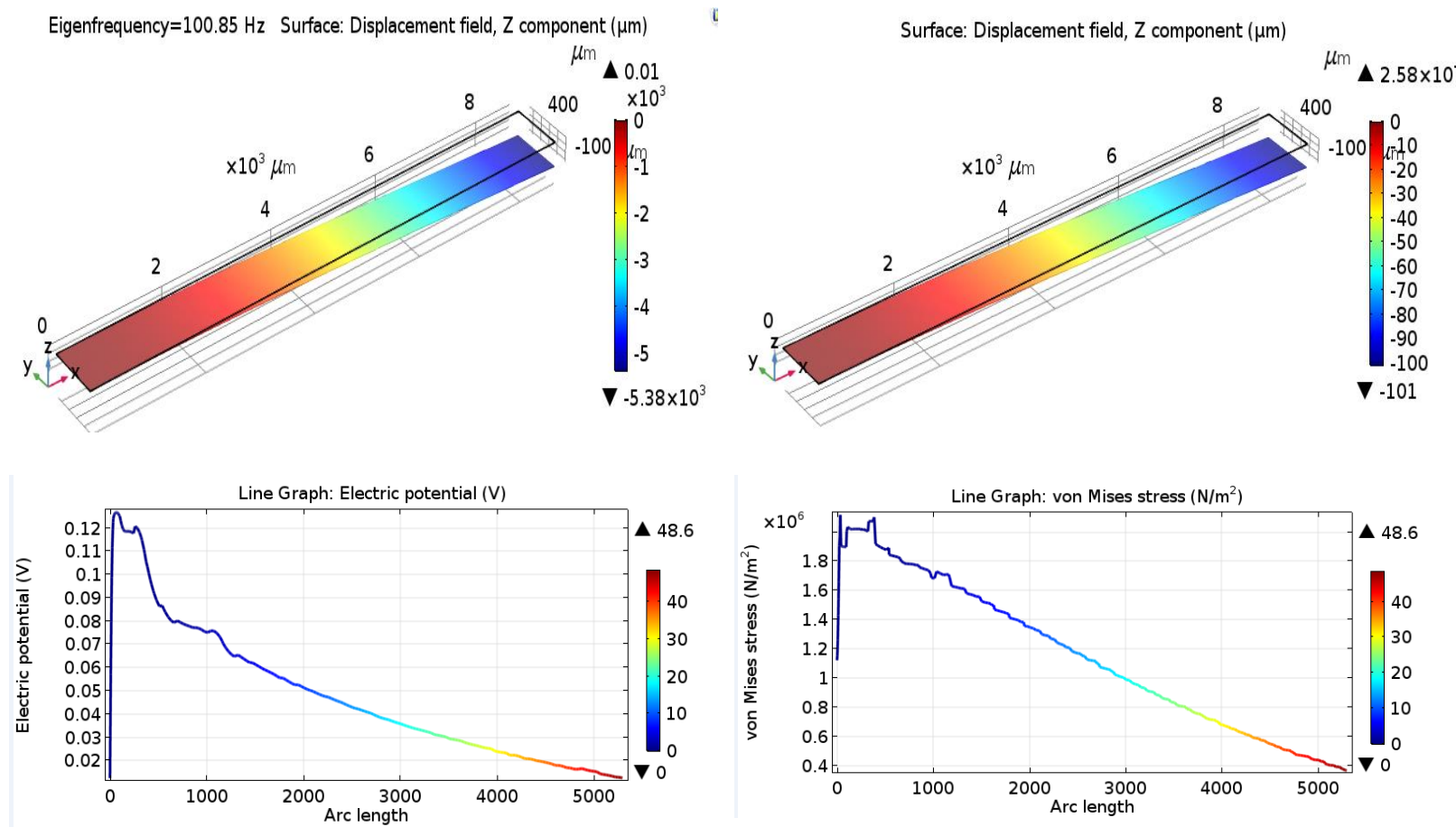

Figure 2. (a) Eigen Frequency, Displacement, Electric Potential and Von Mises stress for Gallium Arsenide (GaAs).

(b)

$$
\begin{aligned}
& S_{d_{1}}=\frac{2}{3} \frac{W t_{s e q} e_{31}}{\omega_{n}^{2}} \\
& k=\frac{8 W D_{1}}{L^{3}} \text { and } \omega_{n}=\sqrt{\frac{k}{m}} \\
& F=\frac{1}{2 \pi} \sqrt{\frac{K}{M}}
\end{aligned}
$$

\section{RESULTS AND DISCUSSION}

The different PZT Materials on MEMS cantilever beam are simulated, the parameters such as displacement, von mises stress and potential voltage for $100 \mathrm{~Hz}$ are compared using COMSOL Multiphysics software [11]. When compared to four materials, the zinc oxide material gave highest potential voltage, displacement and von mises stress when compared to others materials due to its high value of piezoelectric coefficients and coefficient of the electromechanical transformation. Hence, Zinc oxide is an excellent material to be used in MEMS Cochlear implants piezoelectric sensor applications 

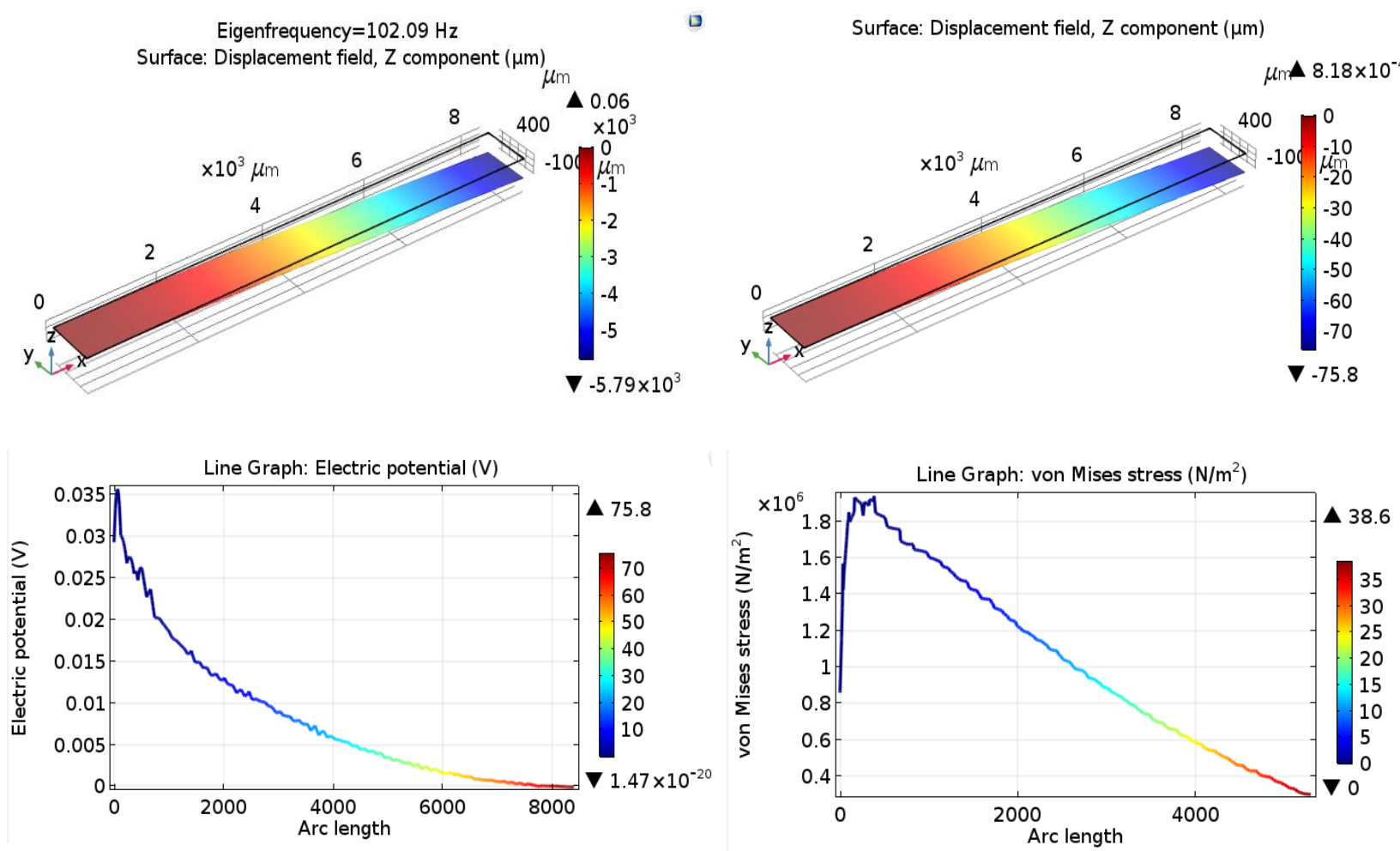

Figure 2. (b) Eigen Frequency, Displacement, Electric Potential and Von Mises stress for Lead Zirconate Titanate(PZT-8)

(c)

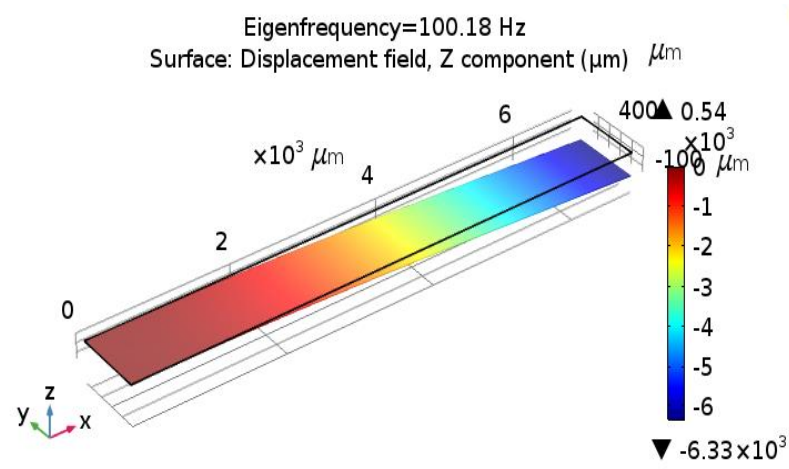

a

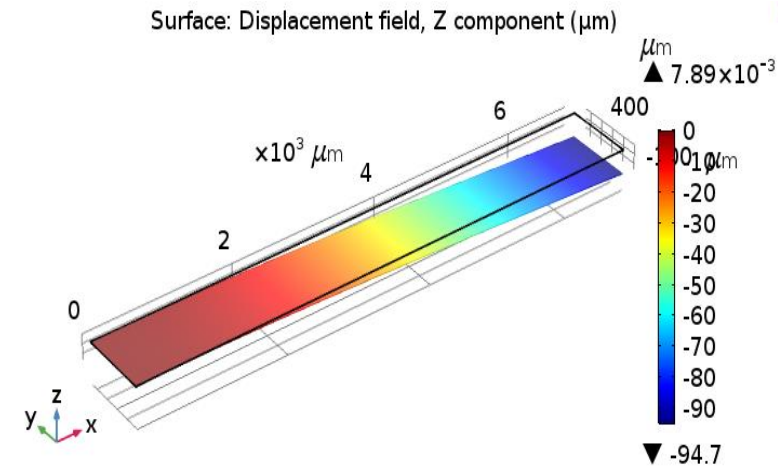

a

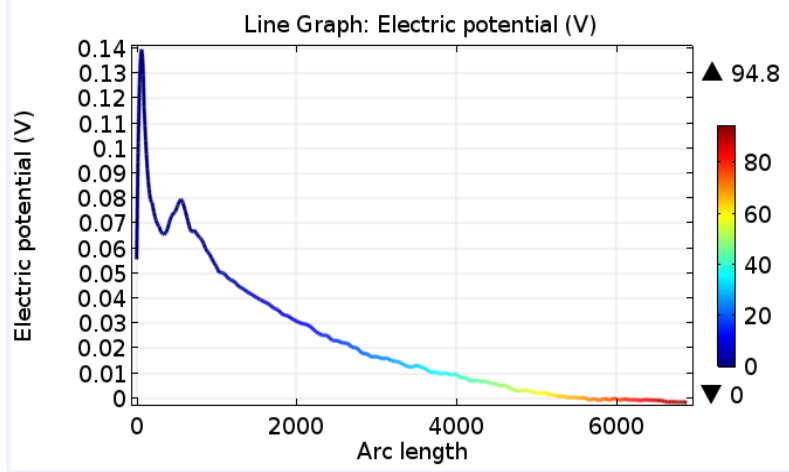

Figure 2. (c) Eigen Frequency, Displacement, Electric Potential and Von Mises stress for Tellurium Dioxide(TeO2) 
(d)
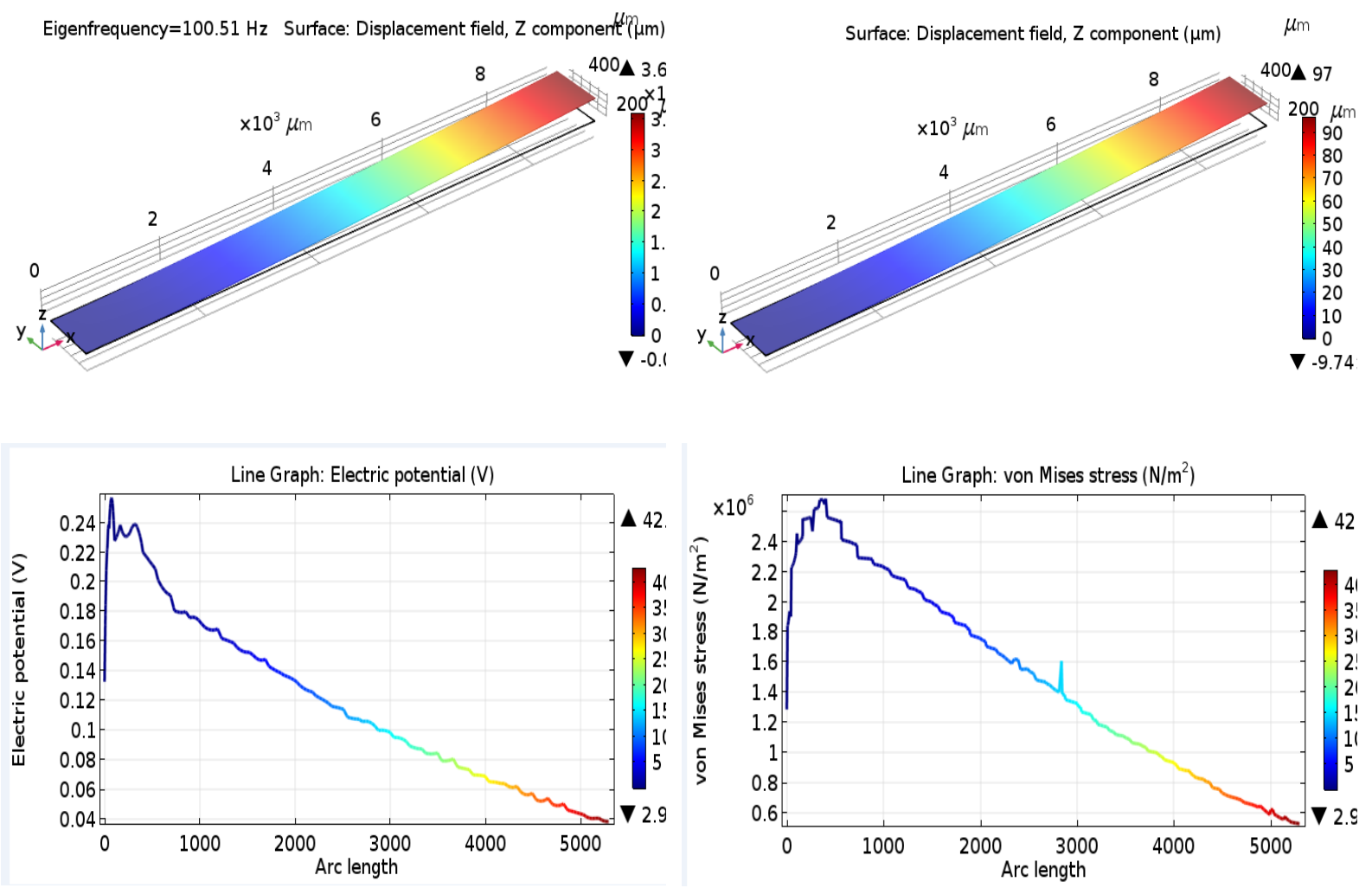

Figure 2. (d) Eigen Frequency, Displacement, Electric Potential and Von Mises stress for Zinc Oxide $(\mathrm{ZnO})$

\begin{tabular}{|l|c|c|c|c|}
\hline \multicolumn{1}{|c|}{ PZT Materials } & Displacement & $\begin{array}{c}\text { Von mises stress } \\
\mathbf{N} / \mathbf{m}^{\mathbf{2}}\end{array}$ & $\begin{array}{c}\text { Potenti } \\
\text { al } \\
\text { Voltage } \\
(\mathbf{m V})\end{array}$ & $\begin{array}{c}\text { Frequen } \\
\mathbf{c y} \\
(\mathbf{H z})\end{array}$ \\
\hline Gallium Arsenide & & & 120 & 100 \\
\hline Lead Zirconate Titanate (PZT-8) & $2.58 \times 10^{-4}$ & $0.18 \times 10^{6}$ & 35.0 & 100 \\
\hline Tellurium Dioxide & $7.89 \times 10^{-4}$ & $1.8 \times 10^{6}$ & 140 & 100 \\
\hline Zinc oxide & $\mathbf{9 7 \times 1 0 ^ { - 6 }}$ & $2.4 \times 10^{6}$ & $\mathbf{2 4 0}$ & $\mathbf{1 0 0}$ \\
\hline
\end{tabular}

\section{Table 3. Simulated different piezoelectric materials parameters for Eigen frequency at $100 \mathbf{H}$}

Fig 2. (a) shows the Eigen frequency at $100 \mathrm{~Hz}$, with a displacement of $258 \mu \mathrm{m}$, maximum electric potential voltage of $120 \mathrm{mV}$ and Von mises stress of $0.18 \times 10^{6} \mathrm{~N} / \mathrm{m}^{2}$ for Gallium arsenide. Fig 2. (b) shows the Eigen frequency at 100 $\mathrm{Hz}$, with a displacement of $818 \mu \mathrm{m}$, maximum electric potential voltage of $35 \mathrm{mV}$ and Von mises stress of $1.8 \times 10^{6} \mathrm{~N} / \mathrm{m}^{2}$ for Lead Zirconate Titanate (PZT-8).Fig 2. (c) shows the Eigen frequency at $100 \mathrm{~Hz}$, with a displacement of $789 \mu \mathrm{m}$, maximum electric potential voltage of $140 \mathrm{mV}$ and Von mises stress of $2.4 \times 10^{6} \mathrm{~N} / \mathrm{m}^{2}$ for Tellurium Dioxide. Fig 2. (d ) shows the Eigen frequency at $100 \mathrm{~Hz}$, with a displacement of $97 \mu \mathrm{m}$, maximum electric potential voltage of $240 \mathrm{mV}$ and Von mises stress of $2.4 \times 10^{6} \mathrm{~N} / \mathrm{m}^{2}$ for Zinc oxide. The results are simulated and analyzed which is tabulated above in Table 2.

\section{CONCLUSION}

This paper deals with designing MEMS cantilever beam with different piezoelectric materials and the simulation results (resonant frequency, displacement, von mises stress) are analyzed and compared using COMSOL Multiphysics software. The proposed geometry can operate at $100 \mathrm{~Hz}$ frequency and the zinc oxide gives the highest electric 
potential of $240 \mathrm{mv}$. Hence Zinc oxide is the excellent and suitable material for the fully cochlear implantable sensor design for further research. This method of MEMS energy harvesting on sensors must be implemented to supply energy to the sensor over its lifetime. MEMS piezoelectric energy harvesting would be a great promise to the future generation in developing and designing sensors in micro scales in all aspects.

\section{FUTURE WORK}

MEMS Implantable sensors are designed to reduce size, low cost and power consumption. They are widely used in biotechnology, medicine, energy harvesting, fluidics, optical and wireless communications, inertial sensing, and consumer product applications. Cochlear Implantable sensors are designed using piezoresistive, piezoelectric, and capacitive accelerometer sensors. In future MEMS cantilever beam using piezoelectric materials is to be designed for fully cochlear implantable sensor.

\section{REFERENCES}

1. Bryzek, J. (1996). Impact of MEMS technology on society. Sensors and Actuators A: Physical, 56(1-2), 1-9.

2. Ho, C. M., \& Tai, Y. C. (1996). MEMS and its applications for flow control.

3. Toshiyoshi, H., Ju, S., Honma, H., Ji, C. H., \& Fujita, H. (2019). MEMS vibrational energy harvesters. Science and technology of advanced materials, 20(1), 124-143.

4. Priya, S., Song, H. C., Zhou, Y., Varghese, R., Chopra, A., Kim, S. G., ... \& Polcawich, R. G. (2017). A review on piezoelectric energy harvesting: materials, methods, and circuits. Energy Harvesting and Systems, 4(1), 3-39. Kim, H. S., Kim, J. H., \& Kim, J. (2011). A review of piezoelectric energy harvesting based on vibration. International journal of precision engineering and manufacturing, 12(6), 1129-1141.

5. Raaja, B. P., Daniel, R. J., \& Sumangala, K. (2017). A simple analytical model for MEMS cantilever beam piezoelectric accelerometer and high sensitivity design for SHM (structural health monitoring) applications. Transactions on Electrical and Electronic Materials, 18(2), 78-88.

6. Devaraju, A., \& Sivasamy, P. (2018). Comparative analysis of mechanical characteristics of sisal fibre composite with and without nano particles. Materials Today: Proceedings, 5(6), 14362-14366.

7. Nechibvute, A., Chawanda, A., \& Luhanga, P. (2012). Finite element modeling of a piezoelectric composite beam and comparative performance study of piezoelectric materials for voltage generation. International Scholarly Research Notices, 2012.

8. Kumar, R. (2017). Design analysis, modeling and simulation of novel rectangular cantilever beam for MEMS sensors and energy harvesting applications. International Journal of Information Technology, 9(3), 295-302.
9. Sunithamani, S., Lakshmi, P., \& Flora, E. E. (2014). PZT length optimization of MEMS piezoelectric energy harvester with a non-traditional cross section: simulation study. Microsystem technologies, 20(12), 2165-2171.

10. Bhaskaran, P. R., Rathnam, J. D., Koilmani, S., \& Subramanian, K. (2017). Multiresonant frequency piezoelectric energy harvesters integrated with high sensitivity piezoelectric accelerometer for bridge health monitoring applications. Smart Materials Research, 2017.

11. Ajitsaria, J., Choe, S. Y., Shen, D., \& Kim, D. J. (2007). Modeling and analysis of a bimorph piezoelectric cantilever beam for voltage generation. Smart Materials and Structures, 16(2), 447.

12. Mohamed, R., Sarker, M. R., \& Mohamed, A. (2016). An optimization of rectangular shape piezoelectric energy harvesting cantilever beam for micro devices. International Journal of Applied Electromagnetics and Mechanics, 50(4), 537-548.

13. Beker, L., Zorlu, Ö., Göksu, N., \& Külah, H. (2013, June). Stimulating auditory nerve with MEMS harvesters for fully implantable and self-powered cochlear implants. In 2013 Transducers \& Eurosensors XXVII: The 17th International Conference on Solid-State Sensors, Actuators and Microsystems (TRANSDUCERS \& EUROSENSORS XXVII) (pp. 1663-1666). I

\section{ACKNOWLEDGEMENT}

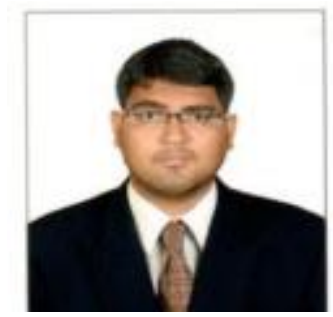

J. Abdul Aziz Khan received the B.E. degree in Electronics and Communication Engineering in 2011 and the M.E degree in Embedded System Technologies in 2015 Affiliated to Anna University, Chennai. He is presently pursuing his Ph.D. in Electronics and Communication Engineering Department at Annamalai University, Chidambaram. His area of research are MEMS Piezoelectric Sensors and Embedded Systems. He is a life member of the Indian Society for Technical Education.

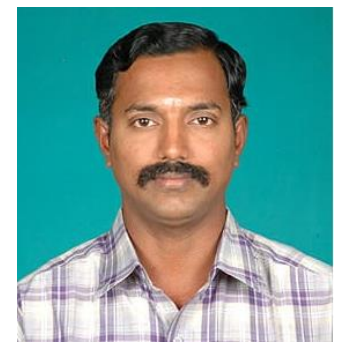

P. Shanmugaraja was born in 1971 in Tirunelveli. He has obtained B.E (Electronics and Communication) from National Engineering College and M.E. (Medical Electronics) from Anna University Chennai, in 1992 and 1995 respectively and then Ph.D. in Micro Electronics from Annamalai university, 
Chidambaram in 2015. He is presently a Professor in Electronics and Instrumentation Engineering Department at Annamalai University where he has put in 24 years of service. $\mathrm{He}$ is presently guiding six Ph.D. scholars and has guided twenty-seven M.E students. His areas of interest are: Nano electronics, Embedded system, Medical electronics. He is a life member of Indian Society for Technical Education and annual Member in Instrumentation Systems and Automation. 